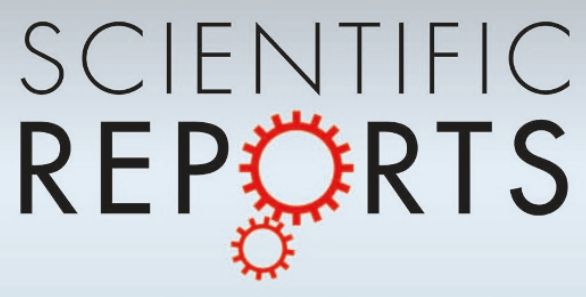

OPEN

CONFERENCE PROCEEDINGS

APEnergy2014 ..............

SUBJECT AREAS: BATTERIES

SYNTHESIS AND PROCESSING NANOPARTICLES

Received 11 February 2014

Accepted

28 March 2014

Published

29 August 2014

Correspondence and requests for materials should be addressed to

Y.C.K. lyckang@ konkuk.ac.kr)

\section{Rapid continuous synthesis of spherical reduced graphene ball-nickel oxide composite for lithium ion batteries}

\author{
Seung Ho Choi, You Na Ko, Jung-Kul Lee \& Yun Chan Kang
}

Department of Chemical Engineering, Konkuk University, 1 Hwayang-dong, Gwangiin-gu, Seoul 143-701, Korea.

In this study, we synthesized a powder consisting of core-shell-structured $\mathrm{Ni} / \mathrm{NiO}$ nanocluster-decorated graphene ( $\mathrm{Ni} / \mathrm{NiO}$-graphene) by a simple process for use as an anodic material for lithium-ion batteries. First, a crumpled graphene powder consisting of uniformly distributed Ni nanoclusters was prepared by one-pot spray pyrolysis. This powder was subsequently transformed into the $\mathrm{Ni} / \mathrm{NiO}$-graphene composite by annealing at $300^{\circ} \mathrm{C}$ in air. The $\mathrm{Ni} / \mathrm{NiO}$-graphene composite powder exhibited better electrochemical properties than those of the hollow-structured $\mathrm{NiO}-\mathrm{Ni}$ composite and pure $\mathrm{NiO}$ powders. The initial discharge and charge capacities of the $\mathrm{Ni} / \mathrm{NiO}$-graphene composite powder were 1156 and $845 \mathrm{~mA} \mathrm{~h} \mathrm{~g}{ }^{-1}$, respectively, and the corresponding initial coulombic efficiency was $73 \%$. The discharge capacities of the Ni/ $\mathrm{NiO}$-graphene, $\mathrm{NiO}-\mathrm{Ni}$, and pure $\mathrm{NiO}$ powders after 300 cycles were 863,647 , and $439 \mathrm{~mA} \mathrm{~h} \mathrm{~g}^{-1}$, respectively. The high stability of the $\mathrm{Ni} / \mathrm{NiO}$-graphene composite powder, attributable to the unique structure of its particles, resulted in it exhibiting long-term cycling stability even at a current density of $1500 \mathrm{~mA} \mathrm{~g}^{-1}$, as well as good rate performance. The structural stability of the $\mathrm{Ni} / \mathrm{NiO}$-graphene composite powder particles during cycling lowered the charge transfer resistance and improved the Li-ion diffusion rate.

E ver since transition metal oxides were first found to be suitable as anodic materials for lithium-ion batteries (LIBs), a number of metal oxides with different structures have been studied extensively ${ }^{1-17}$. Generally, metal oxides that exhibit high theoretical capacities have poor $\mathrm{Li}^{+}$storage/release properties, owing to the large changes that occur in their volume during cycling and because of their low electrochemical conductivities $^{1-17}$. Of the various transition metal oxides being investigated, $\mathrm{NiO}$ has attracted particular attention as a promising anodic material for LIBs, as it is abundantly available, and exhibits low toxicity, high volumetric energy density, and superior safety ${ }^{18-31}$. However, $\mathrm{NiO}$ also exhibits poor rate performance and cyclability owing to slow kinetics of its conversion reaction and its low electronic conductivity ${ }^{18-31}$. NiO-Ni composite materials have been studied in order to improve upon the electrochemical properties of $\mathrm{NiO}^{18-20}$. Composites comprising ultrafine Ni nanoclusters embedded in an active $\mathrm{NiO}$ matrix exhibit high initial Coulombic efficiency, facilitating the decomposition of $\mathrm{Li}_{2} \mathrm{O}$ and the solid-electrolyte interface (SEI) film formed during the charge/discharge process ${ }^{18-20}$. In addition, $\mathrm{Ni}$ can improve the electrochemical properties of $\mathrm{NiO}$ as $\mathrm{NiO}-\mathrm{Ni}$ composite materials exhibit high electronic conductivities. Consequently, $\mathrm{Ni}$ when used as an additive results in NiO-Ni composite materials that exhibit high reversible discharge capacities, initial Coulombic efficiencies, cycling stabilities, and rate capabilities as anodic materials in $\mathrm{LIBs}^{18-20}$. In recent years, graphene-based metal oxide composites have also been studied widely for use as high-capacity anodic materials for $\mathrm{LIBs}^{33-37}$. Graphene, owing to its excellent mechanical, thermal, and electrical properties, can be used to improve the electrochemical conductivities of metal oxides and can be exploited as a buffer layer in anodic materials. Thus, NiO-graphene composite materials, which exhibit high capacities, have also been investigated for use as anodic materials for LIBs ${ }^{26-32}$. However, to the best of our knowledge, NiO-graphene composite materials that show long-term stability and high rate performances have not yet been reported.

In this study, we fabricated a powder consisting of graphene decorated with core-shell-structured $\mathrm{Ni} / \mathrm{NiO}$ nanoclusters ( $\mathrm{Ni} / \mathrm{NiO}$-graphene) by a simple process for use as anodic materials for LIBs. The detailed formation mechanism of the novel-structured $\mathrm{Ni} / \mathrm{NiO}$-graphene composite powder was also investigated. First, a powder of crumpled graphene uniformly covered with Ni nanoclusters was prepared by one-pot spray pyrolysis in a nitrogen atmosphere. Then, this $\mathrm{Ni}$-graphene composite was transformed into the $\mathrm{NiO} / \mathrm{Ni}$-graphene composite through annealing at $300^{\circ} \mathrm{C}$ in air. The electrochemical properties of the $\mathrm{NiO} / \mathrm{Ni}$-graphene composite powder 
were compared with those of a hollow-structured $\mathrm{NiO}-\mathrm{Ni}$ composite as well as with those of a pure $\mathrm{NiO}$ powder prepared by the same process in the absence of graphene. It was found that $\mathrm{Ni}$ metal as well as graphene improved the electrochemical properties of $\mathrm{NiO}$.

\section{Results}

The formation mechanism of the powder consisting of graphene decorated with core-shell-structured $\mathrm{Ni} / \mathrm{NiO}$ nanoclusters (i.e., the $\mathrm{Ni} / \mathrm{NiO}$-graphene powder) is described in Figure 1. First, a $\mathrm{Ni}$ nitrate-graphene oxide composite powder was produced by drying droplets of a nickel nitrate solution containing graphene oxide sheets in a nitrogen atmosphere. The decomposition of nickel nitrate into nickel oxide was also performed in a nitrogen atmosphere, and the reducing atmosphere, attributable to the graphene sheets, reduced the nickel oxide nanoclusters into nanoclusters of $\mathrm{Ni}$ metal. Graphene was formed by the thermal reduction of the graphene oxide sheets at the high temperature of $800^{\circ} \mathrm{C}$. The graphene oxide/graphene sheets prevented the growth of the $\mathrm{NiO} / \mathrm{Ni}$ nanoclusters within the composite powder. The graphene powder with spherical particles and a uniform distribution of Ni nanoclusters could be prepared by one-pot spray pyrolysis even when the reaction time was as small as $10 \mathrm{~s}$. The Ni-graphene composite powder was then annealed at the low temperature of $300^{\circ} \mathrm{C}$ in air, resulting in the partial oxidation of the $\mathrm{Ni}$ nanoclusters. This also prevented the decomposition of the graphene. The oxidation of the outer part of the $\mathrm{Ni}$ nanoclusters resulted in the formation of the Ni-NiO coreshell nanoclusters. Consequently, the annealing of the Ni-graphene composite powder resulted in the fabrication of the core-shell-structured $\mathrm{Ni} / \mathrm{NiO}$ nanocluster-decorated graphene $(\mathrm{Ni} / \mathrm{NiO}$-graphene) powder.

The hollow-structured $\mathrm{NiO}-\mathrm{Ni}$ composite powder was prepared by the one-pot spray pyrolysis of a solution of nickel nitrate and sucrose. The decomposition of the sucrose and nickel nitrate in a nitrogen atmosphere produced a hollow-structured $\mathrm{NiO}$-carbon composite as an intermediate product in the front part of the reactor. Simultaneously, sucrose was oxidized by the nitrate anions, resulting in carbon dioxide, nitrogen, and nitrogen dioxide, as well as water, in large amounts ${ }^{38}$. The abrupt evolution of these gases owing to the decomposition of sucrose and nickel nitrate was what produced the hollow-structured powder particles. The reduction of $\mathrm{NiO}$ into $\mathrm{Ni}$ owing to the consumption of carbon occurred at the rear of the reactor. The fact that the carbonization of sucrose produced carbon in an insufficient amount is what resulted in the hollow-structured carbon-free NiO-Ni composite powder. Finally, a hollow-structured $\mathrm{NiO}$ powder was prepared by the spray pyrolysis of a solution of nickel nitrate that did not contain either graphene oxide or sucrose. The thermal decomposition of this nickel nitrate solution in a nitrogen atmosphere resulted in the fabrication of a powder consisting of hollow-structured $\mathrm{NiO}$ particles with thick shells.

The XRD patterns of the powders prepared from the various types of spray solutions, obtained before and after annealing in air, are shown in Figure S1. The particles of the powders prepared by the one-pot spray pyrolysis of solutions containing graphene oxide and sucrose primarily had crystal structures similar to those of $\mathrm{Ni}$ and $\mathrm{NiO}$, respectively, while the particles of the powder prepared using the spray solution that did not contain a carbon source had a pure$\mathrm{NiO}$-like crystal structure. In the case of the Ni-graphene composite powder, the oxidation of a large amount of $\mathrm{Ni}$ into $\mathrm{NiO}$ occurred after annealing at $300^{\circ} \mathrm{C}$ in air, resulting in the formation of the $\mathrm{Ni} /$ $\mathrm{NiO}$-graphene composite powder, as shown in Figure S1b. On the other hand, the hollow-structured $\mathrm{NiO}-\mathrm{Ni}$ composite powder did not undergo oxidation because of the dense structure of its particles, which were impermeable to the gases produced during the process. The Ni nanoclusters embedded in the $\mathrm{NiO}$ matrix were stable at the low annealing temperature of $300^{\circ} \mathrm{C}$. Therefore, the hollow-structured NiO-Ni powder particles exhibited the same crystal structure before and after the annealing treatment. The XRD pattern of the $\mathrm{NiO}$ powder prepared from the spray solution of nickel nitrate that did not contain graphene oxide or sucrose was similar to that of pure $\mathrm{NiO}$. Figure S2 shows the XPS spectrum for the $\mathrm{Ni} / \mathrm{NiO}$-graphene composite powders. The peak at $854.2 \mathrm{eV}$ binding energy was very close to those for the corresponding peaks in the $\mathrm{Ni} 2 \mathrm{p}_{3 / 2}$ spectrum for pure $\mathrm{NiO}^{39,40}$. The XPS spectrum did not show a shoulder peak at $852.9 \mathrm{eV}$, attributable to metallic Ni. Therefore, Ni metal did not exist on the surface of the $\mathrm{Ni} / \mathrm{NiO}$ nanocrystals dispersed all over the graphene $e^{40}$. However, the XRD pattern, as shown in Figure S1, indicated that the $\mathrm{Ni} / \mathrm{NiO}$-graphene composite powders contained $\mathrm{Ni}$ and $\mathrm{NiO}$ mixed crystal structures. Taken together, the XPS and XRD spectra demonstrated that the $\mathrm{Ni} / \mathrm{NiO}$ nanocrystal core-shell structure was dispersed all over the graphene.

Figure 2 shows the morphology of the $\mathrm{Ni} / \mathrm{NiO}$-graphene composite powder prepared by the two-step process. The SEM and lowresolution TEM images shown in Figures $2 a-2 c$ suggest that the composite powder particles had a crumpled structure. $\mathrm{Ni} / \mathrm{NiO}$ nanoclusters several nanometers in size were uniformly distributed all over the graphene powder particles, as shown in the TEM and dotmapping images. In addition, $\mathrm{Ni}$ and carbon were also uniformly distributed all over the particles of the composite powder, as can be seen from the dot-mapping images. Figure S3 shows the thermogravimetric (TG) curves of the powder. The total decrease in the weight of the $\mathrm{Ni} / \mathrm{NiO}$-graphene composite powder at $700^{\circ} \mathrm{C}$ was $4 \mathrm{wt} \%$. The decrease in its weight owing to the decomposition of graphene was reduced because of the weight increase resulting from the oxidation of $\mathrm{Ni}$ into $\mathrm{NiO}$. Therefore, the graphene content of the composite powders was higher than $4 \mathrm{wt} \%$. The EDX spectrum of the Ni/NiOgraphene composite powders as shown in Figure S4a shows the clear peak of carbon. The two peaks in the Raman spectrum of the Ni/ $\mathrm{NiO}$-graphene composite powder (see Figure S5), observed at 1350 and $1590 \mathrm{~cm}^{-1}$, correspond to the D and $\mathrm{G}$ bands of graphene, respectively. Graphene was formed by the thermal reduction of graphene oxide during the preparation of the $\mathrm{Ni} / \mathrm{NiO}$-graphene composite powder via spray pyrolysis.

Figure 3 shows the morphology of the hollow-structured $\mathrm{NiO}-\mathrm{Ni}$ composite powder prepared from the spray solution containing
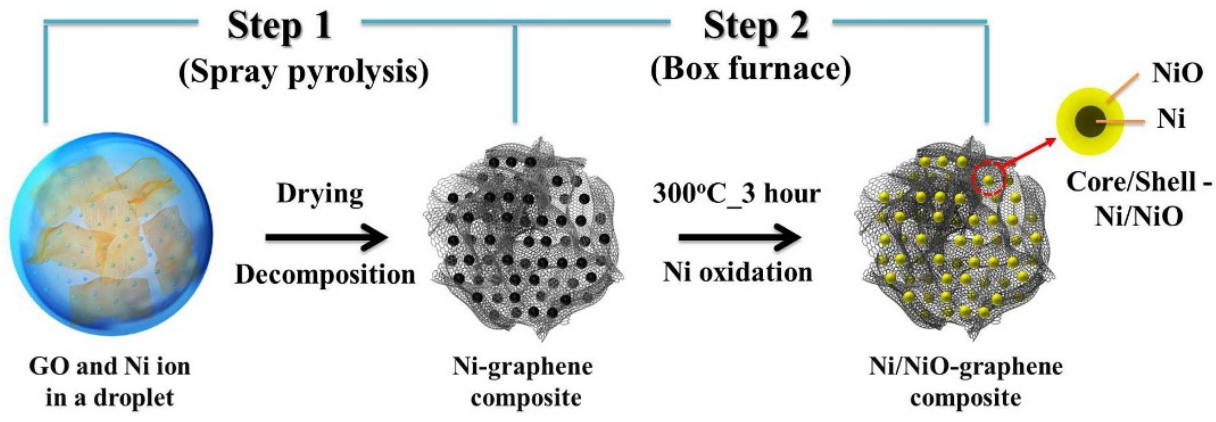

Figure 1 | Formation mechanism of core-shell structured $\mathrm{Ni} / \mathrm{NiO}$ nanocluster-decorated graphene (Ni/NiO-graphene) composite powder. 

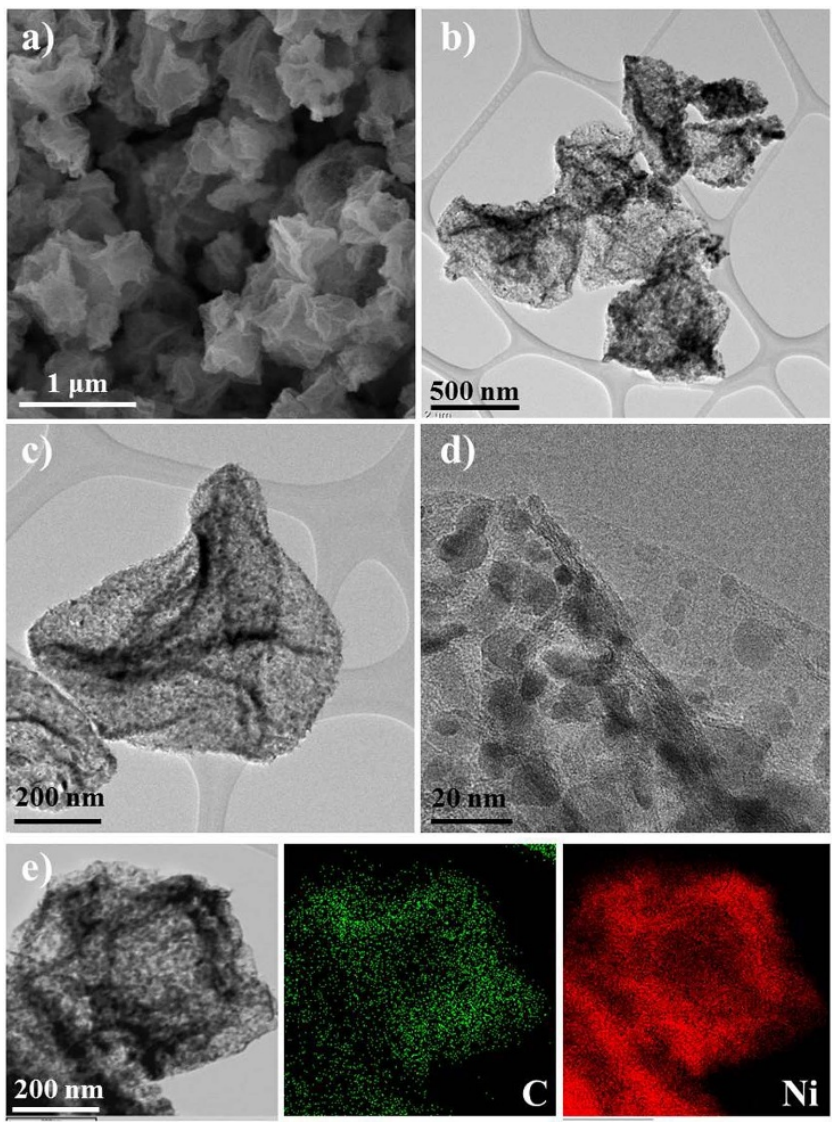

Figure $2 \mid$ Morphologies and dot-mapping images of the Ni/NiOgraphene composite powders prepared by two-step process: (a) SEM, (b)(d) TEM, and (e) dot-mapping images.

nickel nitrate and sucrose. The SEM and TEM images show the powder particles had a hollow structure and thin walls. The highresolution TEM images shown in Figures $3 c$ and $3 d$ reveal that the nanocrystals, which were several tens of nanometers in size, did not form large aggregates. The high-resolution TEM image inset in Figure $3 \mathrm{~d}$ reveals that the clear lattice fringes of the powder were separated by $0.24 \mathrm{~nm}$; this value corresponds to the (111) crystal plane of $\mathrm{NiO}^{22}$. The carbon component was could barely be detected in the dot-mapping images shown in Figure 3e. Figure S4b shows the EDX spectrum of the NiO-Ni composite powder that is shown in Figure $3 \mathrm{e}$; in this case too, the carbon component originating from the carbon grid was not observed. No carbon-related peaks were observed in the spectrum. The weight increase of the NiO-Ni composite powder owing to the oxidation of $\mathrm{Ni}$ into $\mathrm{NiO}$ was $3.2 \mathrm{wt} \%$, as determined from the TG curve shown in Figure S3. The $\mathrm{Ni} / \mathrm{NiO}$ weight ratio of the $\mathrm{NiO}-\mathrm{Ni}$ composite powder as calculated from the TG data was 12/88. Figure S6 shows the morphology of the pure $\mathrm{NiO}$ powder prepared directly by the spray pyrolysis of a solution of nickel nitrate that did not contain a carbon source. The SEM image shows that the particles of the $\mathrm{NiO}$ powder had a hollow structure. The mean sizes of the particles of the $\mathrm{NiO}-\mathrm{Ni}$ and $\mathrm{NiO}$ powders shown in Figure 3 and Figure S6 were 2.2 and $1.3 \mu \mathrm{m}$, respectively. The gases that evolved during the decomposition of sucrose increased the mean size and degree of hollowness of the $\mathrm{NiO}-\mathrm{Ni}$ powder particles.

The electrochemical properties of the three powder samples are shown in Figure 4. Figure 4a shows the cyclic voltammograms (CVs) of the $\mathrm{Ni} / \mathrm{NiO}$-graphene composite powder for the first three cycles at a scan rate of $0.1 \mathrm{mV} \mathrm{s}^{-1}$ for voltages of $0.001-3 \mathrm{~V}$. A single primary anodic peak was observed at approximately $0.53 \mathrm{~V}$; this corresponded to the initial reduction of $\mathrm{NiO}$ to metallic $\mathrm{Ni}$ and the
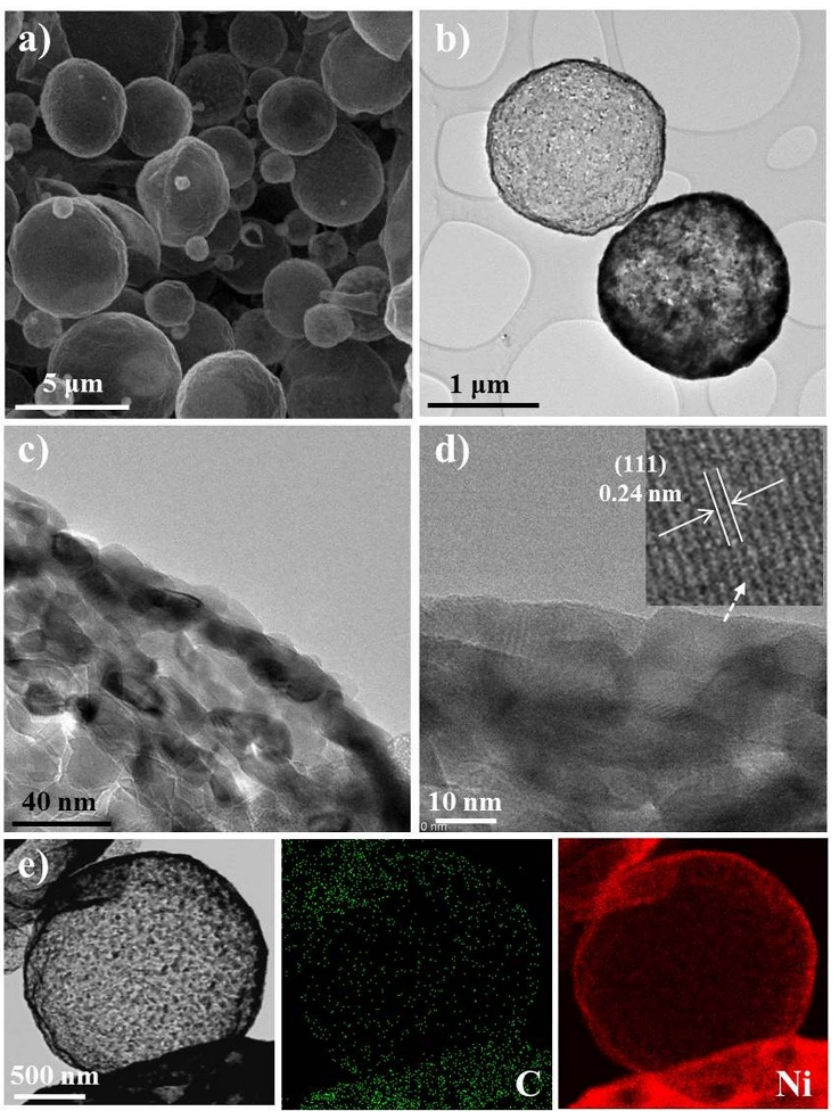

Figure 3 Morphologies and dot-mapping images of the hollow structured NiO-Ni composite powders: (a) SEM, (b)-(d) TEM, and (e) dot-mapping images.

formation of amorphous $\mathrm{Li}_{2} \mathrm{O}$ and a solid-electrolyte interface (SEI) layer ${ }^{26-29}$. In addition, two broad oxidation peaks were observed, at 1.5 and $2.3 \mathrm{~V}$, respectively, during the first charging process; these corresponded to the oxidation of the $\mathrm{Ni}$ nanograins to $\mathrm{NiO}$ and the subsequent decomposition of the SEI layer ${ }^{26-29}$. The main reduction peak shifted to approximately $1.2 \mathrm{~V}$ after the first cycle. From the second cycle onward, the reduction and oxidation peaks exhibited substantial overlap. Figure $4 \mathrm{~b}$ shows the first and second charge/ discharge curves of the $\mathrm{Ni} / \mathrm{NiO}$-graphene and $\mathrm{NiO}-\mathrm{Ni}$ composite powders. The operating cut-off voltages were 0.001 and $3 \mathrm{~V}$, respectively, at a constant current density of $1500 \mathrm{~mA} \mathrm{~g}^{-1}$. The potential of the NiO-Ni composite powder decreased sharply to $0.5 \mathrm{~V}$ and then remained constant over the rest of the initial discharge curve. However, the potential of the $\mathrm{Ni} / \mathrm{NiO}$-graphene composite powder decreased gradually to $0.53 \mathrm{~V}$ during the initial discharging process. The fact that Li could be inserted readily into the particles of the $\mathrm{Ni}$ / $\mathrm{NiO}$-graphene composite powder at high voltages was due to the fact that ultrafine $\mathrm{NiO} / \mathrm{Ni}$ nanoclusters were dispersed in the graphene matrix, resulting in high electrical conductivity. During the first discharge and charge processes, the $\mathrm{NiO}$ particles transformed into amorphous $\mathrm{NiO}$ nanocrystals, irrespective of their original structure. Therefore, the second discharge curves of the $\mathrm{Ni} / \mathrm{NiO}$-graphene and NiO-Ni composite powders had similar shapes, unlike those corresponding to the first discharge cycle. In the second cycle, the wide potential plateau, which can be seen in the first discharge curve, was replaced by a sloping curve that extended from $1.7 \mathrm{~V}$ to $0.8 \mathrm{~V}$. The initial discharge and charge capacities of the $\mathrm{Ni} / \mathrm{NiO}$-graphene composite powder were 1156 and $845 \mathrm{~mA} \mathrm{~h} \mathrm{~g}{ }^{-1}$, respectively, and the corresponding initial Coulombic efficiency was $73 \%$. The initial discharge and charge capacities of the $\mathrm{NiO}-\mathrm{Ni}$ composite powder were 1009 and $759 \mathrm{~mA} \mathrm{~h} \mathrm{~g}^{-1}$, respectively, and the corresponding initial 

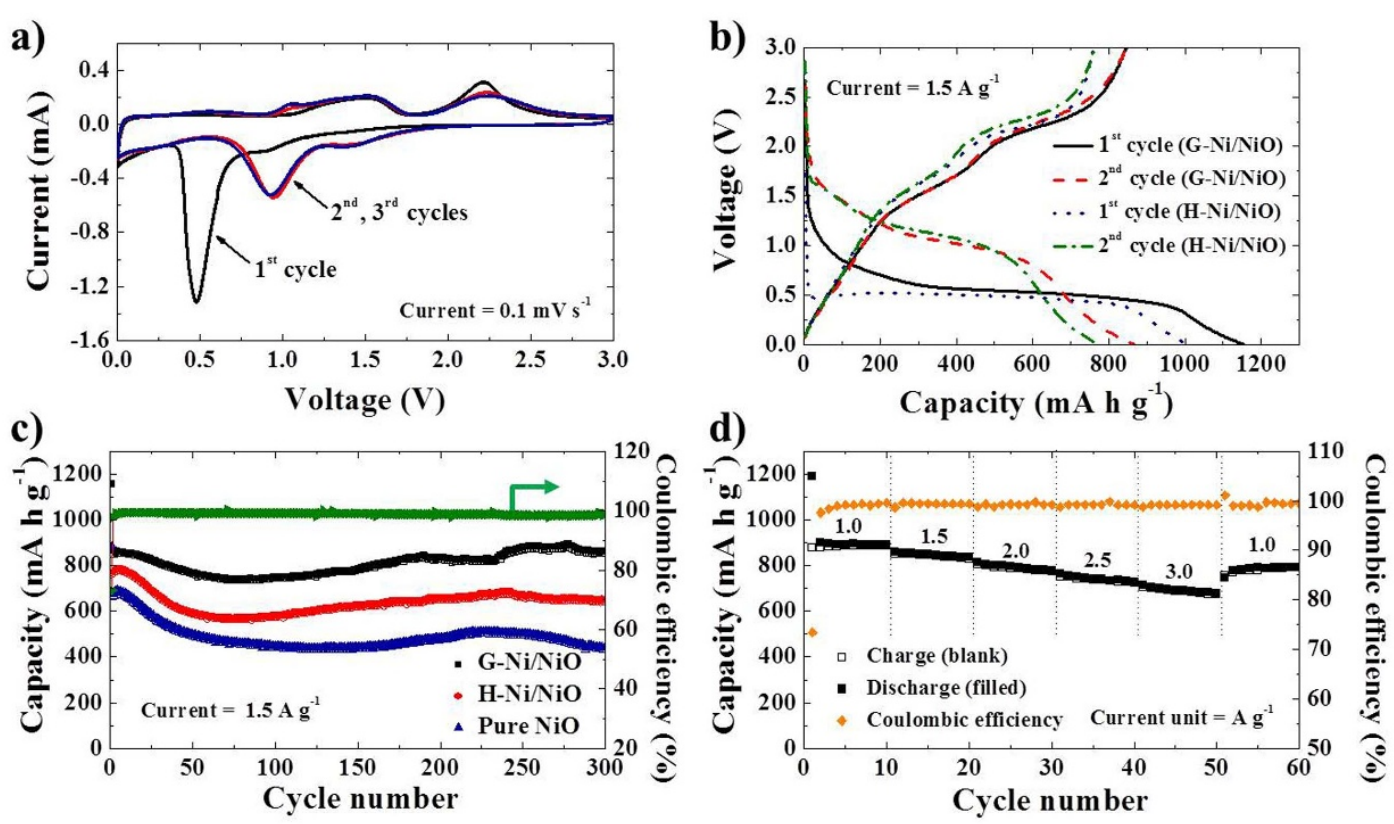

Figure 4 | Electrochemical properties of the three type samples: (a) cyclic voltammograms of the Ni/NiO-graphene, (b) first and second charge/ discharge curves of the $\mathrm{Ni} / \mathrm{NiO}$-graphene and $\mathrm{NiO}-\mathrm{Ni}$, (c) cycling performances at a current density of $1500 \mathrm{~mA} \mathrm{~g}^{-1}$, and (d) rate performance and Coulombic efficiencies of the $\mathrm{Ni} / \mathrm{NiO}$-graphene composite powders.

Coulombic efficiency was $75 \%$. The $\mathrm{Ni} / \mathrm{NiO}$-graphene composite powders showed slightly lower initial Coulombic efficiency than the NiO-Ni composite powders because of the graphene component, which showed low initial Coulombic efficiency. However, the lowgraphene-content $\mathrm{Ni} / \mathrm{NiO}$-graphene composite powders showed higher initial Coulombic efficiencies than those previously reported for $\mathrm{NiO}$-graphene composite powders ${ }^{26-32}$.

Figure $4 \mathrm{c}$ shows the cycling performances of the three powders at a current density of $1500 \mathrm{~mA} \mathrm{~g}^{-1}$. The discharge capacities of the $\mathrm{NiO}$ $\mathrm{Ni}$ composite powder, which had a high $\mathrm{Ni} / \mathrm{NiO}$ weight ratio, increased for the first 5 cycles, and then decreased sharply for the next 70 cycles. This decrease in the discharge capacity was inevitable, given the microscale structural damage that is incurred by $\mathrm{NiO}$ powders at high current densities, starting at the first cycle. Therefore, the increase in the discharge capacities of the NiO-Ni composite powder was due to the gradual activation of the Ni metal during the first 5 cycles as shown in Figure S7. The step-by-step activation of $\mathrm{Ni}$ retarded the decrease in the discharge capacity of the $\mathrm{Ni} / \mathrm{NiO}$-graphene composite powder for the first several cycles. The discharge capacity of the pure $\mathrm{NiO}$ powder also increased slightly for the first 4 cycles. In the case of the pure $\mathrm{NiO}$ powder, the incomplete lithiation of the thick $\mathrm{NiO}$ layer at a high current density of $1500 \mathrm{~mA} \mathrm{~g}^{-1}$ during the first discharge process increased the discharge capacity during the first 4 cycles. However, an increase in the discharge capacity was not observed in the case of the $\mathrm{Ni} / \mathrm{NiO}$ graphene composite powder, owing to its low $\mathrm{Ni}$ content. The decrease in the discharge capacity of the $\mathrm{Ni} / \mathrm{NiO}$-graphene composite powder was lower than those in the cases of the $\mathrm{NiO}-\mathrm{Ni}$ composite and pure $\mathrm{NiO}$ powders during the first 70 cycles. This was because of the structural stability of the $\mathrm{Ni} / \mathrm{NiO}$-graphene composite powder. The graphene layers reduced the change in the volume of the coreshell structured $\mathrm{Ni} / \mathrm{NiO}$ nanoclusters and prevented the growth of $\mathrm{Ni}$ crystals during cycling. The discharge capacities of the $\mathrm{Ni} / \mathrm{NiO}$-graphene, $\mathrm{NiO}-\mathrm{Ni}$, and pure $\mathrm{NiO}$ powders after 300 cycles were 863 , 647 , and $439 \mathrm{~mA} \mathrm{~h} \mathrm{~g}^{-1}$, respectively. The Coulombic efficiency of the $\mathrm{Ni} / \mathrm{NiO}$-graphene composite powder is also shown in Figure $4 \mathrm{c}$. The Coulombic efficiency of the $\mathrm{Ni} / \mathrm{NiO}$-graphene composite powder stayed high, at greater than $99 \%$, after the $3^{\text {th }}$ cycle. Figure S8 shows
SEM images of the $\mathrm{Ni} / \mathrm{NiO}$-graphene and $\mathrm{NiO}-\mathrm{Ni}$ composite powders after they had been subjected to 300 charge/discharge cycles at a current density of $1500 \mathrm{~mA} \mathrm{~g}^{-1}$. The overall structure of the $\mathrm{Ni} / \mathrm{NiO}$ graphene composite powder particles remained unchanged even after 300 cycles. On the other hand, the spherical particles of the NiO-Ni composite powder, which had smooth surfaces, transformed into particles with a crumpled structure after cycling. Owing to its high structural stability, the $\mathrm{Ni} / \mathrm{NiO}$-graphene composite powder exhibited long-term stability even at a current density of $1500 \mathrm{~mA}$ $\mathrm{g}^{-1}$. The highly dispersed $\mathrm{Ni}$ nanoclusters in the $\mathrm{Ni} / \mathrm{NiO}$-graphene composite resulted in the more complete decomposition of the $\mathrm{Li}_{2} \mathrm{O}$ formed during the discharging process. The decomposition process can be represented by the following reaction: $\mathrm{Ni}+\mathrm{Li}_{2} \mathrm{O} \rightarrow \mathrm{NiO}+$ $\left.2 \mathrm{Li}^{+}+2 \mathrm{e}^{-}\right)^{18-20}$. The $\mathrm{Ni}$ nanoclusters in the Ni/NiO-graphene composite powder acted as highly conductive pathways for electron transfer during the conversion reaction of $\mathrm{NiO}$ with $\mathrm{Li}^{+18-20}$.

Figure $4 \mathrm{~d}$ shows the rate performance of the $\mathrm{Ni} / \mathrm{NiO}$-graphene composite powder. The current density was increased from $1000 \mathrm{~mA} \mathrm{~g}^{-1}$ to $3000 \mathrm{~mA} \mathrm{~g}^{-1}$ in a stepwise manner, and then decreased to $1000 \mathrm{~mA} \mathrm{~g}^{-1}$. The $\mathrm{Ni} / \mathrm{NiO}$-graphene composite powder exhibited a second discharge capacity of $899 \mathrm{~mA} \mathrm{~h} \mathrm{~g}^{-1}$ at a current density of $1000 \mathrm{~mA} \mathrm{~g}^{-1}$. Even at a high current density of $3000 \mathrm{~mA}$ $\mathrm{g}^{-1}$, the discharge capacity of the $\mathrm{Ni} / \mathrm{NiO}$-graphene composite powder was as high as $700 \mathrm{~mA} \mathrm{~h} \mathrm{~g}^{-1}$ after 40 cycles, when the current density was increased in a stepwise manner. The discharge capacity decreased with an increase in the number of cycles for current densities of 1500-3000 $\mathrm{mA} \mathrm{g}^{-1}$; this was owing to the structural damage incurred by the powder particles, as described previously (see Figure $4 \mathrm{c}$ ). Therefore, the $\mathrm{Ni} / \mathrm{NiO}$-graphene composite powder had a better rate performance than that shown in Figure 4d. Finally, the $\mathrm{Ni} / \mathrm{NiO}$-graphene composite powder exhibited Coulombic efficiencies greater than $99 \%$ even at high current densities.

\section{Discussion}

Electrochemical impedance spectroscopy was performed to elucidate the $\mathrm{Li}^{+}$ion transfer behaviors of the $\mathrm{Ni} / \mathrm{NiO}$-graphene and $\mathrm{NiO}-\mathrm{Ni}$ composite powders. The Nyquist impedance plots of the powders, obtained before cycling and after 100 cycles, are shown in Figure 5. In 
the case of the $\mathrm{Ni} / \mathrm{NiO}$-graphene composite powder, the diameter of the semicircular curve, which is indicative of the charge-transfer resistance $\left(R_{c t}\right)$ and was obtained before cycling for medium-range frequencies, was greater than that in the case of the NiO-Ni composite powder, as can be seen from Figure $5 \mathrm{a}$. The $R_{c t}$ value of the $\mathrm{Ni}$ / $\mathrm{NiO}$-graphene composite powder, which had a high BrunauerEmmett-Teller (BET) surface area, was larger than that of the $\mathrm{NiO}-\mathrm{Ni}$ composite powder before cycling. The BET surface areas of the $\mathrm{Ni} / \mathrm{NiO}$-graphene and $\mathrm{NiO}-\mathrm{Ni}$ composite powders were 40.7 and $10.6 \mathrm{~m}^{2} \mathrm{~g}^{-1}$, respectively. The $R_{c t}$ value of the $\mathrm{Ni} / \mathrm{NiO}$-graphene composite powder decreased after cycling because its particles became amorphous after 100 cycles. On the other hand, the $R_{c t}$ value of the NiO-Ni composite powder increased after 100 cycles. The decrease in the $R_{c t}$ value owing to the formation of particles with an amorphous structure was diminished by the increase resulting from the change in particle structure during cycling ${ }^{41,42}$. Figures $5 \mathrm{c}$ and $5 \mathrm{~d}$ show the relationship between the real part of the impedance $\left(Z_{\text {re }}\right.$ ) and $\omega^{-1 / 2}$ (where $\omega$ is the angular frequency, $\omega=2 \pi \mathrm{f}$ ) in the low-frequency region before cycling and after $100 \mathrm{cycles}^{42-44}$. That the slope, $\sigma$, which is the Warburg impedance coefficient of the $Z_{\text {re }}$ versus $\omega^{-1 / 2}$ curve, was low indicates that the Li-ion diffusion rate of the $\mathrm{Ni} / \mathrm{NiO}$-graphene composite powder was high ${ }^{40-42}$. The structural stability of the $\mathrm{Ni} / \mathrm{NiO}$-graphene composite powder during cycling lowered the charge-transfer resistance and improved the Li-ion diffusion rate. The electrochemical properties of the Ni/ $\mathrm{NiO}$-graphene composite powders prepared using spray pyrolysis were compared to those of the $\mathrm{NiO}$-graphene composite materials previously reported in the literature, and the results are summarized in Table S1. The Ni/NiO-graphene composite powders showed higher initial discharge capacities and better cycling performances than the previously reported $\mathrm{NiO}$-graphene composite materials. The highly conductive Ni metal and graphene were responsible for the superior electrochemical properties of the $\mathrm{Ni} / \mathrm{NiO}$-graphene composite powders.

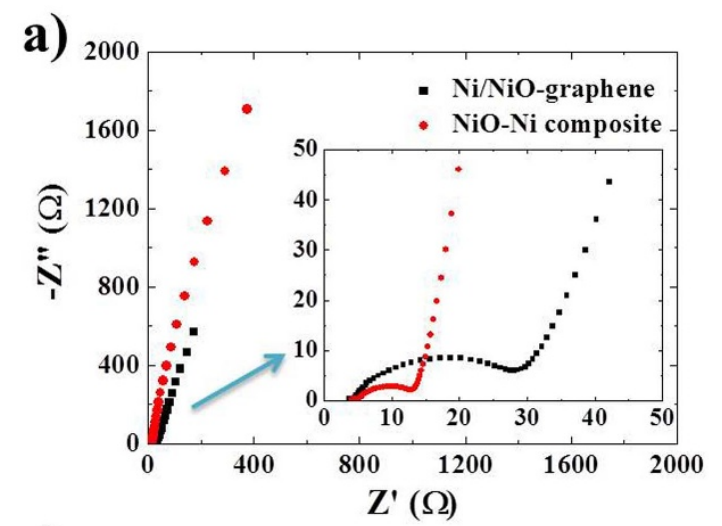

c)

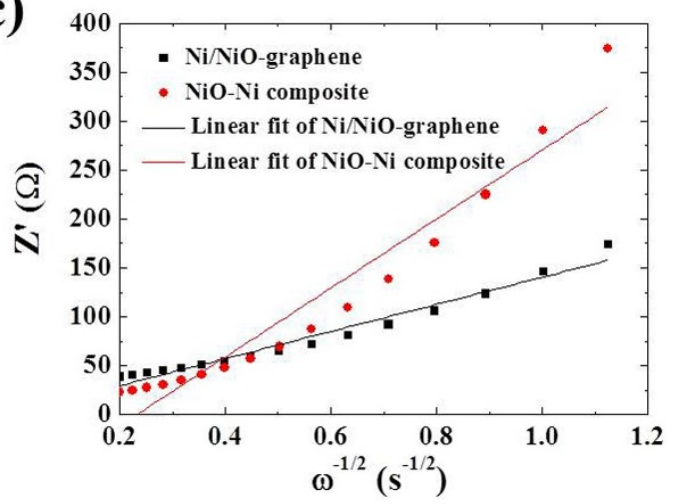

In summary, a powder consisting of crumpled graphene covered with uniformly distributed core-shell-structured $\mathrm{Ni} / \mathrm{NiO}$ nanoclusters was prepared by spray pyrolysis. The electrochemical properties of the $\mathrm{Ni} / \mathrm{NiO}$-graphene composite powder were compared with those of $\mathrm{NiO}-\mathrm{Ni}$ composite and pure $\mathrm{NiO}$ powders prepared by the same process. The $\mathrm{Ni} / \mathrm{NiO}$-graphene composite powder exhibited higher initial discharge and charge capacities and better cycling performance than those of the $\mathrm{NiO}-\mathrm{Ni}$ composite and pure $\mathrm{NiO}$ powders. In addition, the $\mathrm{NiO}-\mathrm{Ni}$ composite powder showed better electrochemical properties than those of the pure $\mathrm{NiO}$ powder, even though the two had similar morphologies. The Ni metal and graphene of the $\mathrm{Ni} / \mathrm{NiO}$-graphene composite were responsible for its superior electrochemical properties. The graphene layers retarded the destroy of the core-shell-structured $\mathrm{Ni} / \mathrm{NiO}$ nanoclusters by large volume change and prevented $\mathrm{Ni}$ crystal growth during cycling.

\section{Methods}

Material fabrication. Synthesis of the solution for spray pyrolysis production of $\mathrm{Ni} /$ $\mathrm{NiO}$-graphene composite. Graphene oxide (GO) was synthesized from graphite flakes by a modified Hummers method ${ }^{12}$. Concentrated $\mathrm{H}_{2} \mathrm{SO}_{4}(120 \mathrm{~mL})$ was added to the graphite flakes $(4 \mathrm{~g})$ and cooled to $0^{\circ} \mathrm{C}$ using an ice bath. $\mathrm{KMnO}_{4}(12 \mathrm{~g})$ was added stepwise to keep the reaction temperature below $10^{\circ} \mathrm{C}$. After removing the solution from the ice bath, it was warmed to $35^{\circ} \mathrm{C}$ and stirred for $30 \mathrm{~min}$, and then distilled water $(120 \mathrm{~mL})$ was slowly added. External heating was introduced to maintain the reaction temperature at $80^{\circ} \mathrm{C}$ for $20 \mathrm{~min}$. Then, the solution was cooled and additional $500 \mathrm{~mL}$ of distilled water $\left(5 \mathrm{wt} \% \mathrm{H}_{2} \mathrm{O}_{2}\right)$ was added. The black precipitate (graphite oxide) was thoroughly washed to remove completely the residual salts and acids and then centrifuged at 4,000 rpm. The as-obtained graphite oxide was redispersed in distilled water and then exfoliated to generate graphene oxide sheets by ultrasonication. Nickel nitrate hexahydrate was dissolved into the colloidal solution of graphite oxide.

Synthesis of $\mathrm{Ni} / \mathrm{NiO}$-graphene composite. The Ni-graphene composite powders were directly prepared by spray pyrolysis. A schematic diagram of the ultrasonic spray pyrolysis system is shown in Figure S9. A quartz reactor of $1200 \mathrm{~mm}$ length and $50 \mathrm{~mm}$ diameter was used, and its temperature was maintained at $800^{\circ} \mathrm{C}$. The flow rate of nitrogen used as carrier gas was $5 \mathrm{~L} \cdot \mathrm{min}^{-1}$. As-prepared Ni-graphene com-
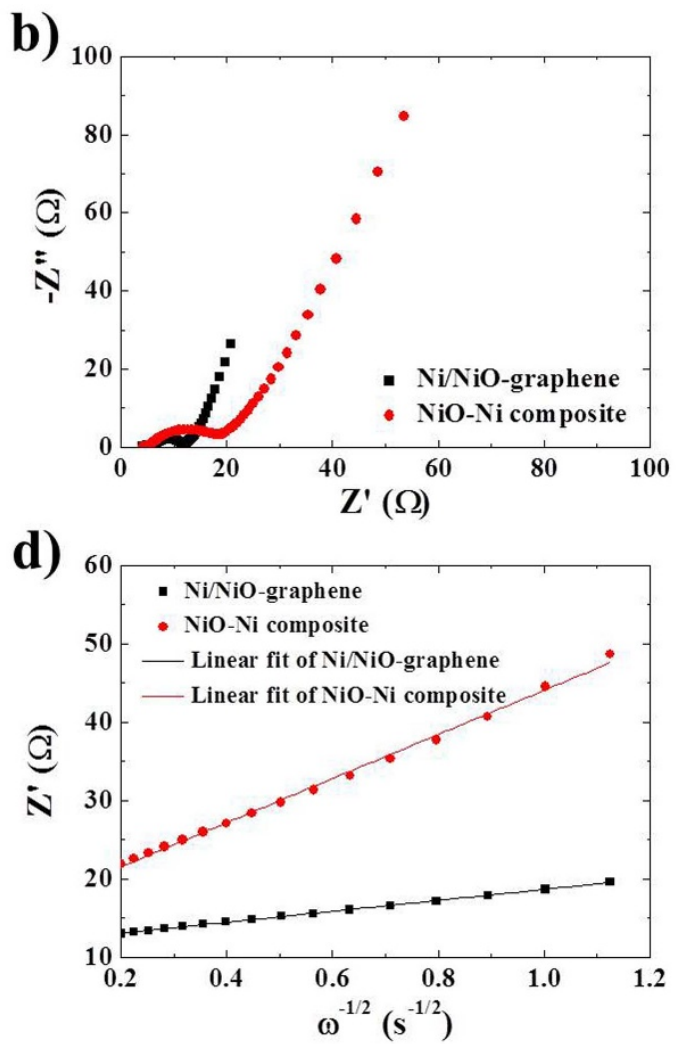

Figure $5 \mid$ Nyquist impedance plots and relationships between real part of the impedance $\left(\mathrm{Z}_{\mathrm{re}}\right)$ and $\omega^{-1 / 2}$ obtained before cycling and after 100 cycles: (a) and (c) before cycling, (b) and (d) after cycling. 
posite powders were post-treated at $300^{\circ} \mathrm{C}$ under an air atmosphere to form the $\mathrm{Ni}$ / $\mathrm{NiO}$-graphene composite powders.

Synthesis of NiO-Ni composite and pure NiO powders. The NiO-Ni composite and pure $\mathrm{NiO}$ powders were directly prepared by spray pyrolysis from the spray solutions with and without sucrose, respectively, at the same preparation conditions for the $\mathrm{Ni}$ graphene composite powders.

Characterization. The crystal structures of the powders were investigated by X-ray diffractometry (XRD, X'pert PRO MPD) using $\mathrm{Cu} \mathrm{K} \alpha$ radiation $(\lambda=1.5418 \AA$ ). Morphological features were investigated using field-emission scanning electron microscopy (FE-SEM, Hitachi S-4800, KBSI Suncheon center) and high-resolution transmission electron microscopy (HR-TEM, JEM-2100F) operating at a working voltage of $200 \mathrm{kV}$. The specific surface areas of the $\mathrm{Ni} / \mathrm{NiO}$-graphene and $\mathrm{NiO}-\mathrm{Ni}$ composite powders were calculated from Brunauer-Emmett-Teller (BET) analysis of nitrogen adsorption measurements (TriStar 3000). The XPS spectra of the powders were investigated using X-ray photoelectron spectroscopy (XPS, ESCALAB-210) with $\mathrm{Al} \mathrm{Ka}$ radiation $(1486.6 \mathrm{eV})$.

Electrochemical measurements. The capacities and cycling properties of the powders were determined using a 2032-type coin cell. The electrode was prepared from a mixture containing $70 \mathrm{wt} \%$ active material, $20 \mathrm{wt} \%$ Super $\mathrm{P}$, and $10 \mathrm{wt} \%$ sodium carboxymethyl cellulose (CMC) binder. Lithium metal and microporous polypropylene film were used as the counter electrode and separator, respectively. The electrolyte was a solution of $1 \mathrm{M} \mathrm{LiPF}_{6}$ in a $1: 1$ volume mixture of ethylene carbonate/dimethyl carbonate (EC/DMC) containing $2 \%$ vinylene carbonate. The charge/discharge characteristics of the samples were determined through cycling in the 0.001-3 V potential range at a set of fixed current densities. Cyclic voltammetry $(\mathrm{CV})$ measurements were carried out at a scan rate of $0.1 \mathrm{mV} \cdot \mathrm{s}^{-1}$. Electrochemical impedance spectroscopy (EIS) was measured using an electrochemical impedance spectroscopy (EIS) over a frequency range of $0.01 \mathrm{~Hz}-100 \mathrm{kHz}$.

1. Poizot, P., Laruelle, S., Grugeon, S., Dupont, L. \& Tarascon, J. M. Nano-sized transition-metal oxides as negative-electrode materials for lithium-ion batteries. Nature 407, 496-499 (2000).

2. Bruce, P. G., Scrosati, B. \& Tarascon, J. M. Nanomaterials for rechargeable lithium batteries. Angew. Chem. Int. Ed. 47, 2930-2946 (2008).

3. Reddy, M. V., Rao, G. V. S. \& Chowdari, B. V. R. Metal oxides and oxysalts as anode materials for Li ion batteries. Chem. Rev. 10, 5364-5457 (2013).

4. Wang, Z., Zhou, L. \& Lou, X. W. Metal oxide hollow nanostructures for lithiumion batteries. Adv. Mater. 24, 1903-1911 (2012).

5. Lai, X. Y., Halpert, J. E. \& Wang, D. Recent advances in micro-/nano-structured hollow spheres for energy applications: from simple to complex systems. Energy Environ. Sci. 5, 5604-5618 (2012).

6. Choi, N. S. et al. Challenges facing lithium batteries and electrical double-layer capacitors. Angew. Chem. Int. Ed. 51, 9994-10024 (2012).

7. Scrosati, B., Hassoun, J. \& Sun, Y. K. Lithium-ion batteries. a look into the future. Energy Environ. Sci. 4, 3287-3295 (2011)

8. Zhang, L., Wu, H. B. \& Lou, X. W. Iron-oxide-based advanced anode materials for lithium-ion batteries. Adv. Energy Mater. 4, 1300958 (2014).

9. Yang, S. B. et al. Porous iron oxide ribbons grown on graphene for highperformance lithium storage. Sci. Rep. 2, 427 (2012).

10. Zeng, L., Zheng, C., Deng, C., Ding, X. \& Wei, M. $\mathrm{MoO}_{2}$-ordered mesoporous carbon nanocomposite as an anode material for lithium-ion batteries. ACS Appl. Mater. Interfaces 5, 2182-2187 (2013).

11. Mao, S. et al. A general approach to one-pot fabrication of crumpled graphenebased nanohybrids for energy applications. ACS Nano 6, 7505-7513 (2012).

12. Choi, S. H. \& Kang, Y. C. Crumpled graphene-molybdenum oxide composite powders: preparation and application in lithium-ion batteries. ChemSusChem 7, 523-528 (2014).

13. Kim, C. J., Noh, M. J., Choi, M. S., Cho, J. P. \& Park, B. W. Critical size of a nano $\mathrm{SnO}_{2}$ electrode for Li-secondary battery. Chem. Mater. 17, 3297-3301 (2005).

14. Park, M. S. et al. Preparation and electrochemical properties of $\mathrm{SnO}_{2}$ nanowires for application in lithium-ion batteries. Angew. Chem. Int. Ed. 46, 750-753 (2007).

15. Chen, S., Bao, P. \& Wang, G. Synthesis of $\mathrm{Fe}_{2} \mathrm{O}_{3}-\mathrm{CNT}$-graphene hybrid materials with an open three-dimensional nanostructure for high capacity lithium storage. Nano Energy 2, 425-434 (2013).

16. Wu, Z. S. et al. Graphene anchored with $\mathrm{Co}_{3} \mathrm{O}_{4}$ nanoparticles as anode of lithium ion batteries with enhanced reversible capacity and cyclic performance. ACS Nano 4, 3187-3194 (2010).

17. Hassan, M. F., Guo, Z. P., Chen, Z. \& Liu, H. K. Carbon-coated $\mathrm{MoO}_{3}$ nanobelts as anode materials for lithium-ion batteries. J. Power sources 195, 2372-2376 (2010).

18. Li, X. F., Dhanabalan, A. \& Wang, C. L. Enhanced electrochemical performance of porous NiO-Ni nanocomposite anode for lithium ion batteries. J. Power sources 196, 9625-9630 (2011).

19. Luo, C. H. et al. Preparation of $\mathrm{C} / \mathrm{Ni} . \mathrm{NiO}$ composite nanofibers for anode materials in lithium-ion batteries. Appl. Phys. A 113, 683-692 (2013).

20. Wen, W., Wu, J. M. \& Cao, M. H. NiO/Ni powders with effective architectures as anode materials in Li-ion batteries. J. Mater. Chem. A 1, 3881-3885 (2013).
21. Su, D., Ford, M. \& Wang, G. Mesoporous $\mathrm{NiO}$ crystals with dominantly exposed $\{110\}$ reactive facets for ultrafast lithium storage. Sci. Rep. 2, 924 (2012).

22. Huang, X. H., Tu, J. P., Zhang, C. Q. \& Xiang, J. Y. Net-structured NiO-C nanocomposite as Li-intercalation electrode material. Electrochem. Commun. 9, 1180-1184 (2007).

23. Varghese, B. et al. Fabrication of $\mathrm{NiO}$ nanowall electrodes for high performance lithium ion battery. Chem. Mater. 20, 3360-3367 (2008)

24. Choi, S. H., Lee, J. H. \& Kang, Y. C. One-pot rapid synthesis of core-shell structured $\mathrm{NiO} @ \mathrm{TiO}_{2}$ nanopowders and their excellent electrochemical properties as anode materials for lithium ion batteries. Nanoscale 5, 12645-12650 (2013).

25. Wei, S. et al. Multifunctional composite core-shell nanoparticles. Nanoscale 3, 4474-4502 (2011).

26. Zhou, G. et al. Oxygen bridges between $\mathrm{NiO}$ nanosheets and graphene for improvement of lithium storage. ACS Nano 4, 3214-3223 (2012).

27. Zou, Y. \& Wang, Y. NiO nanosheets grown on graphene nanosheets as superior anode materials for Li-ion batteries. Nanoscale 3, 2615-2620 (2011).

28. Mai, Y. J. et al. NiO-graphene hybrid as an anode material for lithium ion batteries. J. Power Sources 204, 155-161 (2012).

29. Kottegoda, I. R. M., Idris, N. H., Lu, L., Wang, J. Z. \& Liu, H. K. Synthesis and characterization of graphene-nickel oxide nanostructures for fast chargedischarge application. Electrochim. Acta 56, 5815-5822 (2011)

30. Qiu, D. et al. Graphene anchored with mesoporous $\mathrm{NiO}$ nanoplates as anode material for lithium-ion batteries. J. Solid State Electrochem. 16, 1889-1892 (2012).

31. Huang, Y. et al. Self-assembly of ultrathin porous $\mathrm{NiO}$ nanosheets/graphene hierarchical structure for high-capacity and high-rate lithium storage. J. Mater. Chem. 22, 2844-2847 (2012).

32. Xie, D. et al. Synthesis of porous $\mathrm{NiO}$-wrapped graphene nanosheets and their improved lithium storage properties. J. Phys. Chem. C 117, 24121-24128 (2013).

33. Gong, Y. et al. Graphene-network-backboned architectures for high-performance lithium storage. Adv. Mater. 25, 3979-3984 (2013).

34. Huang, X., Qi, X., Boey, F. \& Zhang, H. Graphene-based composites. Chem. Soc. Rev. 41, 666-686 (2012).

35. Luo, J. Y. et al. Crumpled graphene-encapsulated Si nanoparticles for lithium ion battery anodes. J. Phys. Chem. Lett. 3, 1824-1829 (2012).

36. Wu, Z. S. et al. Graphene/metal oxide composite electrode materials for energy storage. Nano Energy 1, 107-131 (2012).

37. Xin, S., Guo, Y. G. \& Wan, L. J. Nanocarbon networks for advanced rechargeable lithium batteries. Accounts Chem. Res. 45, 1759-1769 (2012)

38. Amarilla, J. M., Rojas, R. M. \& Rojo, J. M. Understanding the sucrose-assisted combustion method: effects of the atmosphere and fuel amount on the synthesis and electrochemical performances of $\mathrm{LiNi}_{0.5} \mathrm{Mn}_{1.5} \mathrm{O}_{4}$ spinel. J. Power Sources 196, 5951-5959 (2011).

39. Xia, X. et al. Fabrication of metal oxide nanobranches on atomic-layer-deposited $\mathrm{TiO}_{2}$ nanotube arrays and their application in energy storage. Nanoscale $\mathbf{5}$, 6040-6047 (2013).

40. Chen, Y. S. et al. Microscopic mechanism for unipolar resistive switching behaviour of nickel oxides. J. Phys. D: Appl. Phys. 45, 065303 (2012).

41. Choi, S. H. \& Kang, Y. C. Yolk-Shell, hollow, and single-crystalline $\mathrm{ZnCo}_{2} \mathrm{O}_{4}$ Powders: preparation using a simple one-pot process and application in lithiumion batteries. ChemSusChem 6, 2111-2116 (2013)

42. Takami, N., Satoh, A., Hara, M. \& Ohsaki, T. Structural and kinetic characterization of lithium intercalation into carbon anodes for secondary lithium batteries. J. Electrochem. Soc. 142, 371-379 (1995).

43. Shi, Y. et al. Hollow structured $\mathrm{Li}_{3} \mathrm{VO}_{4}$ wrapped with graphene nanosheets in situ prepared by a one-pot template-free method as an anode for lithium-ion batteries. Nano Lett. 13, 4715-4720 (2013).

44. Ko, Y. N., Park, S. B., Jung, K. Y. \& Kang, Y. C. One-pot facile synthesis of antcave-structured metal oxide-carbon microballs by continuous process for use as anode materials in Li-ion batteries. Nano Lett. 15, 5462-5466 (2013).

\section{Acknowledgments}

This work was supported by the National Research Foundation of Korea (NRF) grant funded by the Korea government (MEST) (No. 2012R1A2A2A02046367). This work was supported by the Energy Efficiency \& Resources Core Technology Program of the Korea Institute of Energy Technology Evaluation and Planning (KETEP), granted financial resource from the Ministry of Trade, Industry \& Energy, Republic of Korea (201320200000420)

\section{Author contributions}

S.H.C., Y.N.K., J.K.L. and Y.C.K. devised the concept, designed the experiment, and wrote the manuscript. S.H.C. and Y.N.K. performed the experiments and analyzed the data. Y.C.K. supervised the project. All authors discussed the results and contributed in this manuscript

\section{Additional information} scientificreports 
Competing financial interests: The authors declare no competing financial interests.

How to cite this article: Choi, S.H., Ko, Y.N., Lee, J.-K. \& Kang, Y.C. Rapid continuous synthesis of spherical reduced graphene ball-nickel oxide composite for lithium ion batteries. Sci. Rep. 4, 5786; DOI:10.1038/srep05786 (2014).

ShareAlike 4.0 International License. The images or other third party material in this article are included in the article's Creative Commons license, unless indicated otherwise in the credit line; if the material is not included under the Creative Commons license, users will need to obtain permission from the license holder in order to reproduce the material. To view a copy of this license, visit http:// creativecommons.org/licenses/by-nc-sa/4.0/ 